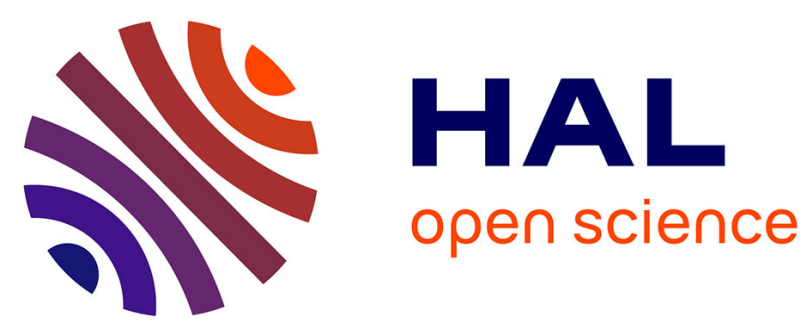

\title{
Spatio-temporal dynamics of glycolytic waves provide new insights into the interactions between immobilized yeast cells and gels
}

\author{
Juraj Bolyó, Thomas Mair, Gabriela Kuncová, Marcus J.B. Hauser
}

\section{To cite this version:}

Juraj Bolyó, Thomas Mair, Gabriela Kuncová, Marcus J.B. Hauser. Spatio-temporal dynamics of glycolytic waves provide new insights into the interactions between immobilized yeast cells and gels. Biophysical Chemistry, 2010, 153 (1), pp.54. 10.1016/j.bpc.2010.10.004 . hal-00702311

HAL Id: hal-00702311

https://hal.science/hal-00702311

Submitted on 30 May 2012

HAL is a multi-disciplinary open access archive for the deposit and dissemination of scientific research documents, whether they are published or not. The documents may come from teaching and research institutions in France or abroad, or from public or private research centers.
L'archive ouverte pluridisciplinaire HAL, est destinée au dépôt et à la diffusion de documents scientifiques de niveau recherche, publiés ou non, émanant des établissements d'enseignement et de recherche français ou étrangers, des laboratoires publics ou privés. 


\section{Accepted Manuscript}

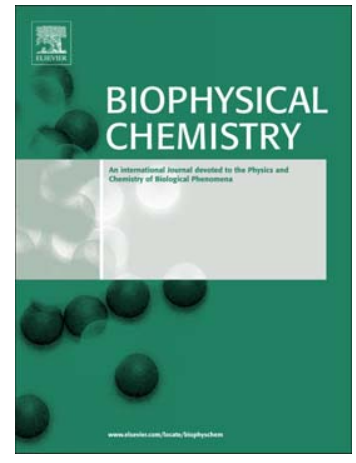

Spatio-temporal dynamics of glycolytic waves provide new insights into the interactions between immobilized yeast cells and gels

Juraj Bolyó, Thomas Mair, Gabriela Kuncová, Marcus J.B. Hauser

PII: $\quad$ S0301-4622(10)00238-3

DOI: $\quad$ doi: $10.1016 /$ j.bpc.2010.10.004

Reference: $\quad$ BIOCHE 5440

To appear in: Biophysical Chemistry

Received date: 25 July 2010

Revised date: $\quad 4$ October 2010

Accepted date: $\quad 5$ October 2010

Please cite this article as: Juraj Bolyó, Thomas Mair, Gabriela Kuncová, Marcus J.B. Hauser, Spatio-temporal dynamics of glycolytic waves provide new insights into the interactions between immobilized yeast cells and gels, Biophysical Chemistry (2010), doi: 10.1016/j.bpc.2010.10.004

This is a PDF file of an unedited manuscript that has been accepted for publication. As a service to our customers we are providing this early version of the manuscript. The manuscript will undergo copyediting, typesetting, and review of the resulting proof before it is published in its final form. Please note that during the production process errors may be discovered which could affect the content, and all legal disclaimers that apply to the journal pertain. 
Spatio-temporal dynamics of glycolytic waves provide new insights into the interactions between immobilized yeast cells and gels

\author{
Juraj Bolyó $^{\mathrm{a}}$, Thomas Mair ${ }^{\mathrm{b}}$, Gabriela Kuncováa ${ }^{\mathrm{a}}$, Marcus J.B. Hauser ${ }^{\mathrm{b}}$
}

${ }^{\mathrm{a}}$ Group of Immobilized Biomaterials and Optical Sensors, Institute of Chemical Process Fundamentals (ICPF), Academy of Sciences of the Czech Republic, Rozvojova 2, 16502 Prague 6, Czech Republic.

${ }^{\mathrm{b}}$ Biophysics Group, Institute of Experimental Physics, Otto-von-Guericke Universität Magdeburg, Universitätsplatz 2, 39106 Magdeburg, Germany.

Corresponding author:

Marcus J. B. Hauser

Biophysics Group

Institute of Experimental Physics

Otto-von-Guericke Universität Magdeburg

Universitätsplatz 2

39106 Magdeburg

Germany

Email: marcus.hauser@ovgu.de

Phone: $+49 / 391 / 6718696$

Fax: $\quad+49 / 391 / 6711181$ 


\begin{abstract}
The immobilization of cells or enzymes is a promising tool for the development of biosensors, yet the interactions between the fixative materials and the cells are not fully understood, especially with respect to their impact on both the cell metabolism and cell-to-cell signaling. We show that the spatiotemporal dynamics of waves of metabolic synchronization of yeast cells provide a new criterion to distinguish the effect of different gels on the cellular metabolism, which otherwise could not be detected. Cells from the yeast Saccharomyces carlsbergensis were immobilised into agarose gel, silica gel (TMOS), or a mixture of TMOS and alginate. We compared these immobilized cells with respect to their ability to generate temporal, intracellular oscillations in glycolysis as well as propagating, extracellular synchronization waves. While the temporal dynamics, as measured by the period and the number of oscillatory cycles, were similar for all three immobilized cell populations, significant differences have been observed with respect to the shape of the waves, wave propagation direction and velocity in the three gel matrices used.
\end{abstract}

Keywords: reaction-diffusion-coupling, pattern formation, metabolic synchronization, open reactor, $\mathrm{NAD}(\mathrm{P}) \mathrm{H}$-fluorescence 


\section{Introduction}

The immobilization of microorganisms has attracted increased scientific interest, since it provides a promising tool for biotechnological applications [1-4]. In addition, immobilized living cells may be used for the construction of biosensors, e.g. in the food industry or in the monitoring of environmental pollution. Several immobilization procedures have been reported [5-12], each having its advantages and drawbacks. One problem concerns the dynamics and regulation of the metabolism, which seems to be affected in the immobilized microorganisms [11-14]. A fast and easy method to test for such perturbations is related to glycolytic oscillations. They are easy to detect by measuring the NAD $(\mathrm{P}) \mathrm{H}$ fluorescence of the immobilized cells and information about the metabolic state of the cells can be derived from characteristic parameters as for example the period and amplitude of the oscillations $[15,16]$. Monitoring of fluorescence intensities of $\mathrm{NAD}(\mathrm{P}) \mathrm{H}$ during aerobic-anaerobic transition has also been used to determine the viability of yeast cells immobilized in transparent matrices. Immobilized cells from the exponential and the stationary growth phases were monitored [13].

Macroscopic glycolytic oscillations of yeast cell populations result from metabolic synchronization of the individual cells [16-18]. These oscillations have a short period of about 0.5-1 min and occur when starved cells of Saccharomyces cerevisiae are supplemented with glucose pulses, either after switching to anaerobiosis [19] or after addition of cyanide, i.e. at energy limiting conditions. Acetaldehyde has been found to act as the signaling compound for this type of cell-cell synchronization. Sustained glycolytic oscillations occur only when the yeast cells are harvested during the diauxic shift [20].

These experiments have been performed with stirred cell suspensions. However, oscillatory systems may generate spatio-temporal patterns when the oscillatory reaction is coupled to mass transport processes, such as diffusion [21,22]. As this is the case in gel-fixed yeast cell layers, the glycolysis in entrapped yeast cells may give rise to a series of waves and patterns, that are well known from self-organized reaction-diffusion systems [22-25]. Metabolic synchronization of gel-fixed cell populations may thus occur via traveling waves of the signaling compound, which cannot form in stirred cell suspensions. Results from chemical systems demonstrate that the propagation dynamics as well as the shape of such traveling reaction-diffusion waves contain information about the state of the system [26,27]. Hence, 
these waves may be of relevance for biological information processing [28,29], and as such also for biotechnological applications.

The first experimental evidence for the generation of reaction-diffusion waves in glycolysis came from experiments with yeast extract [30,31]. There, traveling NADH and proton waves could be observed during oscillatory glycolysis. In these experiments, the necessary coupling between reaction and diffusion was achieved by performing the glycolytic reaction in a gel matrix. A drawback of these investigations is that they have been conducted under batch conditions. Since the generation of oscillations and reaction-diffusion waves requires nonequilibrium conditions, such experiments are best run in open reactors [32].

Recently, Bagyan et al. monitored reaction-diffusion waves in the yeast extract immobilized in an agarose gel mounted into an open spatial reactor [33]. They could show that in case of the yeast extract local desynchronization plays an important role for the wave dynamics [34]. Lavrova et al have simulated glycolytic wave propagation in this open spatial reactor in order to explain some of the phenomena observed at low protein concentrations [35]. Due to the possibility of maintaining the reaction under stationary non-equilibrium conditions, this reactor should also be useful for the measurement of oscillations and waves in yeast cell suspensions.

In the present work, we show first results about the application of this type of reactor for cell suspensions immobilized in gels with a focus of the impact of various gel matrices on the dynamics of glycolytic patterns. We aimed at investigating (i) the effect of the immobilizing gel medium on the generation of glycolytic oscillations in yeast cells and on (ii) the spatiotemporal patterns that may arise in immobilized cell layers, i.e. when there is a coupling between reaction and diffusion. Three different gel matrices were used: agarose, prepolymerized tetramethoxysilane (TMOS) and compositions of pre-polymerized tetramethoxysilane with alginate (alginate/TMOS). 


\section{Materials and methods}

\section{Growth of yeast}

The yeast Saccharomyces carlsbergensis ATCC 9080 was cultivated aerobically in a rotary shaker at $180 \mathrm{rpm}$ in liquid semi-synthetic minimal media [36] at $28{ }^{\circ} \mathrm{C}$. After complete consumption of glucose the cells were harvested by centrifugation at $5000 \times \mathrm{g}$ at $21^{\circ} \mathrm{C}$ for 5 min and were washed twice with distilled water. The cells were resuspended in potassium phosphate buffer $\left(0.1 \mathrm{M} \mathrm{KH}_{2} \mathrm{PO}_{4}, \mathrm{pH} 6.5\right)$ yielding cell suspensions in concentrations of 10 , 20 or $30 \%$ (wet weight per volume). Subsequently, these cell suspensions were starved at $21^{\circ} \mathrm{C}$ for at least $6 \mathrm{~h}$ until further use.

Gel preparation and immobilization procedure

After at least $6 \mathrm{~h}$ of starvation, the yeast cells were immobilized in one of the following three gel matrices that were prepared as follows:

$1 \%$ agarose gel: Agarose (Type VII; Sigma-Aldrich) $(0.03 \mathrm{~g})$ in potassium phosphate buffer (1.5 mL of $0.1 \mathrm{M} \mathrm{KH}_{2} \mathrm{PO}_{4}, \mathrm{pH} 6.5$ ) was heated for $5 \mathrm{~min}$ at $70^{\circ} \mathrm{C}$. The solution was placed in a water bath at $28^{\circ} \mathrm{C}$. After $2 \mathrm{~min}$, the cell suspension $\left(1.5 \mathrm{~mL}\right.$; incubation at $\left.28^{\circ} \mathrm{C}\right)$ was carefully mixed with the agarose and subsequently this mixture was placed between two glass plates $(20 \mathrm{~cm} \times 15 \mathrm{~cm})$ separated by $1.5 \mathrm{~mm}$ thick spacers. The gelation process took place during $15 \mathrm{~min}$ at $\mathrm{ca} .0^{\circ} \mathrm{C}$. A flat surface of the gel was obtained by placing a $5 \mathrm{~kg}$ weight on the upper glass plate during the gelation process. Thereafter a circular piece (diameter $24 \mathrm{~mm}$ ) of the gel slide was cut out and placed on a black nitrocellulose membrane (Millipore) of 0.8 $\mu \mathrm{m}$ pore size [33].

Silica gel: Tetramethoxysilane (TMOS; Fluka) was mixed with distilled water and $\mathrm{HCl}(0.1$ M) in TMOS: $\mathrm{H}_{2} \mathrm{O}: \mathrm{HCl}$ molar ratio $=1: 5: 10^{-2}$, to form a clear solution. This solution was left to pre-polymerize for $24 \mathrm{~h}$ at $4^{\circ} \mathrm{C}[13,37]$. The pre-polymerized TMOS was used for immobilization in the following way: The cell suspension $(1 \mathrm{~mL})$ was mixed with $0.05 \mathrm{M}$ $\mathrm{NaOH}(0.5 \mathrm{~mL})$ and with pre-polymerized TMOS $(0.5 \mathrm{~mL})$. This mixture was vortexed and poured on the black nitrocellulose membrane which was covered with an appropriate spacer ring (diameter $24 \mathrm{~mm}$, teflon). After gelation (within ca. 1-2 min, at room temperature), 
planar film disks (of $24 \mathrm{~mm}$ diameter and $15 \mathrm{~mm}$ thickness) of immobilized cells were very quickly cut out and the spacer ring was removed.

Alginate/TMOS matrix: At first a stock solution of sterile $3.2 \%(\mathrm{w} / \mathrm{v})$ sodium alginate (Sigma-Aldrich, type IV, practical grade) was prepared as follows: the alginate and distilled water were sterilized separately $\left(20 \mathrm{~min}, 120^{\circ} \mathrm{C}, 0.1 \mathrm{kPa}\right)$. Thereafter, the sterilized alginate was dissolved in the sterilized distilled water under sterile conditions and stored at $4{ }^{\circ} \mathrm{C}$ until further use. For preparation of the gel the cell suspension $(1 \mathrm{~mL})$ was mixed with $0.05 \mathrm{M}$ $\mathrm{NaOH}(0.5 \mathrm{~mL})$, dissolved alginate $(0.167 \mathrm{~mL})$ and pre-polymerized TMOS $(0.333 \mathrm{~mL})$. Then this mixture was very quickly vortexed and poured on the black nitrocellulose membrane covered with an appropriate spacer ring (diameter $24 \mathrm{~mm}$, teflon). After gelation (within ca. 1-2 min at room temperature) the biofilm was immersed into a $\mathrm{CaCl}_{2}$ solution (7 $\mathrm{g} / \mathrm{L}$ ) for $30 \mathrm{~min}$ [13,37]. Subsequently, planar (disk) films of immobilized cells $(24 \mathrm{~mm}$ diameter and $15 \mathrm{~mm}$ thickness) were cut out and the spacer ring was removed.

\section{Monitoring of glycolytic activity}

The glycolytic activity of yeast cells was measured under two different conditions: (i) in stirred suspensions in a conventional spectrophotometer and (ii) in gel-fixed suspensions in an open spatial reactor, i.e. at unstirred conditions. For both systems the glycolytic activity was measured by the $\mathrm{NAD}(\mathrm{P}) \mathrm{H}$ fluorescence at excitation and emission wave lengths $\lambda=366$ and $460 \mathrm{~nm}$, respectively.

(i) Glycolytic oscillations in stirred cell suspensions. $1.9 \mathrm{ml}$ of $10 \%(\mathrm{w} / \mathrm{v})$ yeast cells were placed in a spectrofluorimeter (AB2 Luminescence spectrophotometer, SLM AMINCO, Milton Roy Co., USA). The cells were stirred in a thermostatically regulated cuvette at $21^{\circ} \mathrm{C}$ (Hellma, Germany). Glycolytic oscillations were initiated by addition of glucose $(0.1 \mathrm{~mL} ; 1$ M) into the cell suspension.

(ii) Glycolytic oscillations and waves from immobilized cells: The immobilized yeast cell discs were placed in an open spatial reactor (Fig. 1). The open spatial reactor consists of diffusive gel layer in contact with the content of a continuous-flow stirred tank reactor (CSTR). This CSTR acts as a feeding reservoir for the immobilized cell layer. The immobilized yeast cells were separated from the CSTR by an Anodisc membrane, with $20 \mathrm{~nm}$ 
pore size (Whatman). The black nitrocellulose membrane and the immobilized yeast cell disc were placed on top of this Anodisc membrane. Glycolytic oscillations of the immobilized yeast cells were initiated by feeding a solution containing $60 \mathrm{mM}$ glucose, $0.1 \mathrm{M} \mathrm{KH}_{2} \mathrm{PO}_{4}, \mathrm{pH}$ 6.5 , and $0.1 \mathrm{mM}$ acetaldehyde into the open spatial reactor. Spatiotemporal concentrations changes of $\mathrm{NAD}(\mathrm{P}) \mathrm{H}$ (i.e. $\mathrm{NAD}(\mathrm{P}) \mathrm{H}$ waves) were monitored by means of an image intensified CCD camera (Corail, Optronics) and the resulting movies digitized at a temporal resolution of 2 images per second with a frame grabber card using a standard personal computer. For further details on the experimental set-up, see Bagyan et al [33].

For analysis of the local temporal dynamics, the intensity of the NAD $(\mathrm{P}) \mathrm{H}$-fluorescence (grey levels) of a selected area (20 x 20 pixels) from each image of the movie was averaged and plotted as a function of time. For analysis of the spatiotemporal dynamics of the glycolytic waves a time-space plot of propagating $\mathrm{NAD}(\mathrm{P}) \mathrm{H}$ waves was constructed from the recorded movies along selected lines. The intensity along the selected line from each image of the movie was stacked on top of each other, resulting in the time-space-plot, which displays the spatiotemporal dynamics of propagating waves along this line. The reciprocal of this line corresponds to the wave velocity. 


\section{Results}

Induction of glycolytic oscillations in stirred yeast cell suspensions

Addition of glucose to starved yeast cells induces glycolytic oscillations, provided the cells are under energy limiting conditions. At the chosen growth conditions of the yeast, a starvation period of about 3-5 h is required, when stirred yeast cells are investigated (Fig. 2). During the starvation period the amplitude of the oscillations increases from 0.12 to $0.31 \mathrm{a}$. u. until it reaches a plateau after about 6-7 h (Fig. 3). On the other hand, the oscillatory period remains relatively constant at $30 \pm 4 \mathrm{~s}$. These values serve as a reference for the experiments with the immobilized cells. For all immobilization experiments we used yeast cells that had been starved for $9 \mathrm{~h}$.

Glycolytic oscillations of immobilized yeast cells in gel matrices

Gel-fixed yeast cells represent a diffusive layer and thus open the possibility to investigate their ability to generate spatiotemporal patterns of the reaction-diffusion type in an open system. To this purpose, the gel layer of the fixed cells is coupled via a membrane to a continuous stirred tank reactor (CSTR), which acts as a feeding reservoir [33] (Fig. 1). The generation of glycolytic patterns in yeast cell layers is expected to occur via extracellular acetaldehyde waves [38]. These extracellular waves, however, can be visualized only indirectly. e. g. via intracellular $\mathrm{NAD}(\mathrm{P}) \mathrm{H}$. Changes in the intracellular $\mathrm{NAD}(\mathrm{P}) \mathrm{H}$ fluorescence can be seen as an indicator for the concentration changes in the extracellular acetaldehyde, because the oscillations of these two compounds exhibit a fixed phase relation [18]. Thus, we have taken the spatiotemporal dynamics of intracellular NAD(P)H fluorescence as an indirect measure of extracellular acetaldehyde waves.

Concomitant application of glucose and acetaldehyde to the gel-fixed yeast cells induces glycolytic oscillations in these cells. Acetaldehyde has been applied together with glucose in order to avoid a drop of its concentration below a critical value [18]. The analysis of local fluorescence changes reveals the generation of glycolytic oscillations, irrespective of the type of gel used (Fig. 4). The period of the glycolytic oscillations (53 s) as well as the number of oscillatory cycles (13-15) is nearly the same in the three gels studied (Fig. 5). However, a comparison of gel-fixed cells with stirred cell suspensions demonstrates a 50\% drop in the period for the stirred cells, whereas the number of cycles remains nearly unaffected (13-15 vs. 
12). Since the period is also related to temporal events we may take this change as an indicator for the slower diffusive processes in the gels, which are overcome by stirring in experiments with cell suspensions.

Spatio-temporal dynamics

In the extended gel-immobilised cell system, we also followed the spatiotemporal distribution of $\mathrm{NAD}(\mathrm{P}) \mathrm{H}$. The signals are very weak so that the signal to noise ratio of the images is quite poor. However, the evaluation of the movies after image processing (background subtraction, contrast enhancement) revealed the spontaneous formation of propagating patterns. They can be seen as white stripes or spots (increased $\mathrm{NAD}(\mathrm{P}) \mathrm{H})$ on a dark background. To improve visualization of the waves we have marked them by dashed lines (Fig, 6A). The direction of wave propagation is indicated by an arrow. With agarose as fixative (Fig $6 \mathrm{~A}, \mathrm{~B}$ ) we observe multiple wave sources which periodically emit waves that eventually combine to one large wave. Similar wave patterns are observed when the yeast cells were immobilized in TMOS (Fig. 6C, D) or in alginate/TMOS. No significant differences in the wave velocity were found in agarose and TMOS (both at $130 \pm 20 \mu \mathrm{m} / \mathrm{s}$ ) gels, whereas in alginate/TMOS the propagation velocity it is about twice as large $(240 \pm 10 \mu \mathrm{m} / \mathrm{s})$.

A further difference between yeast cells immobilized in silica (TMOS) and agarose gel at the one side and cells entrapped in alginate/TMOS gel is the direction of propagation of the glycolytic waves (Fig. 6). While waves in agarose and silica gels were found to propagate from the centre of the reactor outwards, waves of cells in alginate/TMOS gels propagate in the opposite direction, i.e. inwardly.

The time-space-plots (Fig. 7) constructed from the movies at three different spatial locations (marked as white lines in Fig. 6B) demonstrate the impact of the type of gel on the wave propagation dynamics. On these time-space plots horizontal lines are due to oscillations in the medium, while inclined white lines originate from propagating $\mathrm{NAD}(\mathrm{P}) \mathrm{H}$ waves. Whereas in agarose the spatial patterns are quite complex even showing several wave dislocations (see arrows Fig. 7A), the patterns in the alginate/TMOS gel are very regular with only minor spatial differences (Fig. 7C). In TMOS alone we can see regular propagating waves mainly in the middle of the gel (Fig. 7B, 1/2), whereas at the borders the waves propagate at lower velocity. 
The impact of the gel composition on the propagation velocity of the waves can be also deduced from the time traces taken from the time-space-plots of figure 7, which are plotted in figure 8 . On average we find a phase shift between the centre and the border of the gel of $7.5 \mathrm{~s}$ for agarose (Fig. 8A), $25.9 \mathrm{~s}$ for TMOS (Fig. 8B) and $0.5 \mathrm{~s}$ for alginate/TMOS (Fig. 8C). 


\section{Discussion}

The results presented here demonstrate for the first time the generation of propagating synchronization waves in yeast cell immobilized into layers of gels. The results also show that the open spatial reactor, used to perform these experiments, is well suited for the investigation of spatiotemporal pattern formation, not only in yeast extract [33-35] but also in yeast cell layers.

Although the use of the open reactor is intended at maintaining the cell population in a sustained oscillatory state, we find only transient oscillations (Fig. 4). This indicates that the cells do not settle on an oscillatory state because some drifts in the reaction conditions cannot be fully controlled. Possibly, either substances required to maintain the glycolytic NAD $(P) H$ oscillations leak out of the gel layer, or substances that inhibit the oscillations accumulate in the gel. Acetaldehyde itself may be a potential candidate for both of these possibilities since a drop below or an increase above the oscillatory concentration window abolishes the oscillations [18].

Supply of glucose to the immobilized cells not only induces temporal glycolytic oscillations but also traveling waves (Fig. 6). This means that there is a coupling between the intracellular oscillatory production of acetaldehyde, which is released into the extracellular medium, and the extracellular transport of the messenger acetaldehyde by diffusion. The propagation dynamics of the travelling waves consequently depend on both, the oscillatory reaction and the transport step. Thus, possible interactions of the gels with the metabolism of the cells (oscillatory glycolysis) as well as with the extracellular signaling compounds (extracellular diffusion of acetaldehyde) may be encoded in these waves.

When comparing the characteristics of the temporal glycolytic NAD $(\mathrm{P}) \mathrm{H}$ oscillations observed in gel-immobilized yeast cells to those of cells in suspension, we observe that the period of oscillations is twice as large in the gel-immobilized cells than in the suspended ones (Fig. 5). Since the glycolytic oscillations are the result of an acetaldehyde-mediated synchronization between the cells [18], stirring of the cell suspensions provides an immediate distribution of this compound into the entire reactor, whereas in the gel the transport of this messenger is provided exclusively by molecular diffusion, which is much slower. Thus, the increased oscillatory period in the gels is caused by the slower diffusion of extracellular 
acetaldehyde. Similar results have been obtained by Doran and Bailey with cells from Saccharomyces cerevisiae, suspended in phosphate buffer or immobilized in gelatin [11]. Although the immobilization procedure and the type of gel differed markedly from ours, a pronounced increase of the period of glucose induced oscillations in intracellular NAD $(\mathrm{P}) \mathrm{H}$ for the cells immobilized in gelatin was also found. When measured at $25{ }^{\circ} \mathrm{C}$, the period rose from $54 \mathrm{~s}$ for suspended cells to about $240 \mathrm{~s}$ for the immobilized cells [11].

In the following, we discuss the influence of the type of gel on both, the temporal and spatiotemporal dynamics of entrapped yeast cells. To this purpose the (i) periods of the temporal oscillations as well as (ii) the direction and (iii) speed of the propagating waves will be discussed. Interestingly the temporal dynamics show no difference among the different gels, although the three gels studied in the present article have different pore sizes. Obviously, the differences in extracellular diffusion in the gel types studied are not sufficiently large to significantly alter the period of oscillations.

The picture changes, when it comes to comparing the spatiotemporal wave patterns of $\mathrm{NAD}(\mathrm{P}) \mathrm{H}$ concentration in the three gels studied (agarose, TMOS, and alginate/TMOS). The wave patterns are relatively similar to each other, thus demonstrating the robustness of oscillatory glycolysis arising even from yeast cells immobilized in gels. Nevertheless, significant differences were found when it comes to the wave propagation direction and velocity, which depend sensitively on the identity of the immobilizing gel. In fact, glycolytic waves from cells entrapped in silica (TMOS) and agarose gels always propagated outwards, while the propagation direction in alginate/TMOS gels was always inward. The difference in wave propagation direction correlates with the behaviour of the wave speed. Again, the wave speeds are similar in agarose and silica gel, while it is twice as high in alginate/TMOS. These observations suggest that the availability of acetaldehyde for the cells entrapped in agarose or silica gels on the one hand and in alginate/TMOS at the other hand differ. This may be due either to subtle differences in the transport efficiency of acetaldehyde, since such changes in the transport process have recently been shown to affect the direction of wave propagation $[34,35]$, or to a different way of entrapping the cells in the gel matrices.

To better understand how the yeast cells are entrapped into the gel matrices, we have performed a preliminary screening electron microscopic (SEM) study, which indicates that the yeast cells are monodispersely entrapped in both agarose and silica gels. This contrasts 
with the alginate/TMOS gel, where the cells are found to form small clusters comprising a small number of cells. The formation of cell clusters in alginate/TMOS matrices may explain the different direction of glycolytic wave propagation in this matrix: In small clusters, the cells are packed tightly together, so that the acetaldehyde released from one cell immediately triggers the release of acetaldehyde of the other cells in the cluster. The clusters are randomly distributed in the gel, and thus act as randomly distributed nucleation sites for wave initiation. Unevenly, but randomly distributed clusters consequently favour the generation of waves that propagate inwardly.

The wave propagation speed is similar for cells entrapped in agarose and silica gels, while the wave velocity is significantly higher in alginate/TMOS gel. This is somewhat surprising, since this composite gel contains weak chemical bonds between the hydroxyl groups of the polymerized aqueous silica and the polysaccharide chains of alginate [39,40]. Therefore the alginate/TMOS gel would have been expected to have a considerably smaller pore sizes than TMOS alone or the agarose gel. In turn, this would than have led to a decreased diffusion and to a lower wave propagation velocity.

However, the more effective transport in alginate/TMOS gels seems to be linked to the cluster formation of yeast cells, which may locally lead to the release of a higher concentration of acetaldehyde than it is the case of monodispersely distributed cells (as in agarose or silica gels). Since the excitation of a yeast cell requires a superthreshold concentration of the messenger acetaldehyde, this threshold is reached sooner when higher concentrations of the messenger are present. This leads to higher effective wave propagation velocity. The more homogeneous appearance of the wave propagation in the alginate/TMOS gel (Fig. 7) is a further indication for a more effective transport of acetaldehyde between the entrapped cells. These findings suggest that there is a stronger mutual coupling of the cells in the alginate/TMOS gel than in the other two gels. Additional support for a more effective acetaldehyde transport in the alginate/TMOS gel is provided by the phase shift between the center and the borders of the gel (Fig. 8). In alginate/TMOS there is nearly no phase shift ( 0.5 s), whereas in agarose we find a phase shift of $7.5 \mathrm{~s}$ and in TMOS of $26 \mathrm{~s}$.

Bagyan et al. [33] found also phase shifts for glycolytic waves, however in immobilized yeast extract, measured with the same open spatial reactor as the one used in the present study. Later, Lavrova et al simulated these results and attributed the phase shifts to a slight 
inhomogeneous substrate inflow [35]. An inhomogeneous distribution of the cells, however, might have a similar effect as an inhomogeneous substrate inflow. Spatial desynchronization phenomena might be taken into consideration as well [34]. Figure 8 also reveals a strong decrease of the amplitude in cells immobilized in alginate/TMOS. However, fluorescence is a relative measure and thus should be taken with care when different experimental conditions are involved.

In conclusion, our results demonstrate that spatiotemporal glycolytic oscillations can be generated in yeast cells that are immobilized in gel layers. This is in good agreement with recent studies where such waves were also seen in sedimented (but not fixated) cells layers, and also with studies where a gel-immobilized cell extracts were used. The spatiotemporal patterns of metabolic synchronization in gel-immobilized yeast cell layers provide a promising tool to investigate the interaction between the cells and the surrounding gel. Especially the wave velocity, direction, and the wave patterns seem to be suitable parameters for this purpose, since these characteristic features were found to depend sensitively from both, the identity of and the physical parameters describing the embedding, fixating gel.

\section{Acknowledgement}

This study was financially supported by the Ministry of Education, Youth and Sport of the Czech Republic (grant no. OC121) and by the Deutsche Forschungsgemeinschaft (grant no. MU5939/19-1). Exchange grant and lab visit support was provided by the ESF research networking program "Functional Dynamics in Complex Chemical and Biological Systems" (FUNCDYN) and by COST action 865 "Bioencapsulation multiscale interaction analysis".

\section{Note added}

We dedicate this article to Dr. Thomas Mair, who sadly passed any during the publication process of this article. 


\section{References}

[1] Avnir, D., Coradin, T., Lev, O., Livage, J.: Recent bio-applications of sol-gel materials. Journal of Materials Chemistry 16 (2006), 1013-1030.

[2] Martynenko, N.N., Gracheva, I.M., Sarishvili, N.G., et al.: Immobilization of champagne yeasts by inclusion into cryogels of polyvinyl alcohol: Means of preventing cell release from the carrier matrix. Applied Biochemistry and Microbiology 40 (2004), $158-164$.

[3] Livage, J., Coradin, T.: Living cells in oxide glasses. Medical Mineralogy and Geochemistry 66 (2006), $315-332$.

[4] Champagne, C.P., Côté, C.B.: Cream fermentation by immobilized lactic acid bacteria. Biotechnology Lettters 9 (1987), 329 - 332.

[5] Gupta, R., Chaudhury, N.K.: Entrapment of biomolecules in sol-gel matrix for applications in biosensors: Problems and future prospects. Biosensors \& Bioelectronics 22 (2007), $2387-2399$.

[6] Pierre, A.C.: The sol-gel encapsulation of enzymes. Biocatalysis and Biotransformation 22 (2004), $145-170$.

[7] Preininger, C., Klimant, I., Wolfbeis, O.S.: Optical Fiber Sensor for Biological Oxygen Demand. Analytical Chemistry 66 (1994), 1841 - 1846.

[8] Naessens, M., Leclere, J.C., Tran-Minh, C.: Fiber Optic Biosensor Using Chlorella vulgaris for Determination of Toxic Compounds. Ecotoxicology and Environmental Safety 46 (2000), $181-185$.

[9] Trogl, J., Ripp, S., Kuncova, G., Sayler, G.S., Churava, A., Parik, P., Demnerova, K., Halova, J., Kubicova, L.: Selectivity of whole cell optical biosensor with immobilized bioreporter Pseudomonas fluorescens HK44. Sensors and Actuators 107 (2005), 98 103.

[10] Gavlasova, P., Kuncova, G., Kochankova, L., Mackova, M.: Whole cell biosensor for polychlorinated biphenyl analysis based on optical detection. International Biodeterioration \& Biodegradation 62 (2008), 304 - 312.

[11] Doran, M.P., Bailey, J.: Effects of Immobilization on the Nature of Glycolytic Oscillations in Yeast. Biotechnology and Bioengineering 29 (1987), 892 - 897.

[12] Poulsen, A.K., Petersen, M.O., Olsen, L.F.: Single cell studies and simulation of cellcell interactions using oscillating glycolysis in yeast cells. Biophysical Chemistry 125 (2007), $275-280$. 
[13] Podrazky, O., Kuncova, G.: Determination of living immobilized yeast cells by fluorescence spectroscopy. Sensors and Actuators B-Chemical 107 (2005), 126 - 134.

[14] Callone, E., Campostrini, R., Carturan, G., Cavazza, A., Guzzon, R.: Immobilization of yeast and bacteria cells in alginate microbeads coated with silica membranes: Procedures, physico-chemical features and bioactivity. Journal of Materials Chemistry 18 (2008), 4839 - 4848.

[15] Goldbeter, A.: Biochemical oscillators and cellular Rhythms. Cambridge University Press, Cambridge, 1996.

[16] Richard, P.: The rhythm of yeast. FEMS Microbiology Reviews 27 (2003), 547 - 557.

[17] Ghosh, A.K., Chance, B., Pye, E.K.: Metabolic Coupling and Synchronization of NADH Oscillations in Yeast Cell Populations. Archives of Biochemistry and Biophysics 146 (1971), 319 - 331.

[18] Richard, P., Bakker, M.B., Teusink, B., Van Dam, K., Westerhoff, H.V.: Acetaldehyde mediates the synchronization of sustained glycolytic oscillations in populations of yeast cells. European Journal of Biochemistry 235 (1996), 238 - 241.

[19] Hess, B., Boiteux, A.: Mechanism of Glycolytic Oscillation in Yeast, I. Aerobic and anaerobic growth conditions for obtaining glycolytic oscillation. Hoppe-Seyler's Zeitschrift für Physiologishe Chemie 349 (1968), 1567 - 1574.

[20] Richard, P., Teusink B., Westerhoff, H.V., van Dam, K.: Around the growth phase transition $S$. cerevisiae's make-up favours sustained oscillations of intracellular metabolites. FEBS Journal 318 (1993), 80 - 82.

[21] Prigogine, I., Nicolis, G.: Biological order, structure and instabilities. Quarterly Review of Biophysics 4 (1971), $107-148$.

[22] Mikhailov, A.S., Showalter, K.: Control of waves, patterns and turbulence in chemical systems. Physics Reports 425 (2006), 79 - 194.

[23] Kapral, R., Showalter, K.: Chemical waves and patterns. Kluwer Academic Publishers, Dordrecht, 1995.

[24] Epstein, I.R., Pojman, J.A.: An introduction to nonlinear chemical dynamics Oscillations, waves, patterns, and chaos. Oxford University Press, Oxford, 1998.

[25] Steinbock, O., Müller, S.C.: Control of chemical waves in excitable media by external perturbation, in Schuster, H.G. (ed.), Handbook of Chaos Control, Wiley-VCH, Weinheim, 1999, pp. $591-614$.

[26] Steinbock, O., Kettunen, P., Showalter, K.: Chemical wave logic gates. Journal of Physical Chemistry 100 (1996), 18970 - 18975. 
[27] Gorecki, J., Gorecka, J.N., Yoshikawa, K., Igarashi, Y., Nagahara, H.: Sensing the distance to a source of periodic oscillations in a nonlinear chemical medium with the output information coded in frequency of excitation pulses. Physical Review E 72 (2005), 046201.

[28] Mair, T., Müller, S.C.: Propagating waves of biological activity. Recent Research Developments in Biophysical Chemistry 1 (2000), $105-121$.

[29] Loose, M., Fischer-Friedrich, E., Ries, J., Kruse, K., Schwille, P.: Spatial regulators for bacterial cell division self-organize into surface waves in vitro. Science 320 (2008), 789 $-792$.

[30] Mair, T., Müller, S.C.: Traveling NADH and proton waves during oscillatory glycolysis in vitro. Journal of Biological Chemistry 271 (1996), 627 - 630.

[31] Mair, T., Warnke, C., Müller, S.C.: Spatio-temporal dynamics in glycolysis. Faraday Discussions 120 (2001), 249 - 259.

[32] Horvath, J., Szalai, I., De Kepper, P.: An experimental design method leading to chemical Turing patterns. Science 324 (2009), $772-775$.

[33] Bagyan, S., Mair. T., Dulos, E., Boissonade, J., De Kepper, P., Müller, S.C.: Glycolytic oscillations and waves in an open spatial reactor: Impact of feedback regulation of phosphofructokinase. Biophysical Chemistry 116 (2005), 67 - 76.

[34] Bagyan S., Mair, T., Suchorski, Y, Hauser, M.J.B., Straube, R.: Spatial desynchronization of glycolytic waves as revealed by Karhunen-Loève analysis. Journal of Physical Chemistry 112 (2008), 14334 - 14341.

[35] Lavrova, A.I., Bagyan, S., Mair, T., Hauser, M.J.B., Schimansky-Geier, L.: Modeling of glycolytic wave propagation in an open spatial reactor with inhomogeneous influx. BioSystems 97 (2009), 127 - 133.

[36] Hess, B., Boiteux, A.: Mechanism of glycolytic oscillation in yeast, 1. Aerobic and anaerobic growth conditions for obtaining glycolytic oscillations. Hoppe-Seylers Zeitschrift fur Physiologishe Chemie 349 (1968), 1567 - 1574.

[37] Kuncova, G., Podrazky, O., Ripp, S., Trogl, J., Sayler, G.S., Demnerova, K., Vankova, R.: Monitoring of the viability of cells immobilized by sol-gel process. Journal of SolGel Science and Technology 31 (2004), 335 - 342.

[38] Schütze, J., Wolf, J.: Spatio-temporal dynamics of glycolysis in cell layers. A mathematical model. Biosystems 99 (2010), 104 - 108.

[39] Coradin, T., Livage, J.: Synthesis and characterization of alginate/silica biocomposites. Journal of Sol-Gel Science and Technology 26 (2003), 1165 - 1168. 
[40] Xu, S.W., Jiang, Z.Y., Lu, Y., Wu, H., Yuan, W.K.: Preparation and catalytic properties of novel alginate-silica-dehydrogenase hybrid biocoposite beads. Industrial and Engineering Chemistry Research 45 (2006), 511 - 517. 


\section{Figure Captions}

Figure 1: Sketch of the open spatial reactor used to perform the experiments with gelimmobilized yeast cell layers.

Figure 2: Glycolytic oscillations in stirred suspensions of S. carlsbergensis (cell concentration: $10 \%$ wet (w/v)) after different times of starvation. Glycolysis was measured by $\mathrm{NAD}(\mathrm{P}) \mathrm{H}$ fluorescence in a conventional spectrofluorimeter. The oscillations were initiated by addition of glucose to the cell suspension (marked by arrow). The yeast cells had been starved for $0-11 \mathrm{~h}$.

Figure 3: Increase of the amplitude of glycolytic oscillations in stirred suspensions of $S$. carlsbergensis (cell concentration: $10 \%$ wet $(\mathrm{w} / \mathrm{v})$ ) as a function of the starvation time. Oscillations have been measured by $\mathrm{NAD}(\mathrm{P}) \mathrm{H}$ fluorescence. The mean value is calculated from 10-12 amplitudes. Error bars show \pm Standard deviation.

Figure 4: Glycolytic oscillations of immobilized cells of $S$. carlsbergensis $(10 \% \mathrm{w} / \mathrm{v})$ in gel matrices. The glycolytic oscillations of the gels were measured in the open spatial reactor (stirring rate: $500 \mathrm{rpm}$, feeding rate: $74 \mathrm{~mL} / \mathrm{h}$ and temperature $21^{\circ} \mathrm{C}$ ). The cells were immobilized after $9 \mathrm{~h}$ of starvation and the oscillations were initiated by addition of glucose and acetaldehyde (at time $180 \mathrm{~s}$, marked by the arrow).

Figure 5: Comparison of the kinetic values of the glycolytic oscillations from the cells shown in figure 2 (after $9 \mathrm{~h}$ starvation) and figure 4 . Period is given in seconds.

Figure 6: Propagating waves of glycolytic activity in immobilized yeast cell layers after glucose addition, as measured by intracellular NAD(P)H-fluorescence. Immobilization was performed in agarose (A, B), TMOS (C, D) and alginate/TMOS (E, D). For improved visualization the wave fronts are marked by dashed lines (in $\mathrm{C}$ with a circle) and the propagation direction by an arrow. In $B$ the three different locations $(1 / 3,1 / 2,2 / 3$ from top to bottom) at which time space plots have been constructed are marked by horizontal full lines. The time interval is $88 \mathrm{~s}$ for $\mathrm{A}$ to $\mathrm{B}, 78 \mathrm{~s}$ for $\mathrm{C}$ to $\mathrm{D}$ and $86 \mathrm{~s}$ for $\mathrm{E}$ to $\mathrm{F}$. The $\mathrm{x}$-axis of each image corresponds to $12 \mathrm{~mm}$. 
Figure 7: Time-space plots of propagating waves in immobilized yeast cell layers (cell concentration: $10 \%(\mathrm{w} / \mathrm{v})$ ) in A) agarose, B) silica (TMOS) gel and C) alginate/TMOS gels. The different locations at which the time space plots were taken $(1 / 3,1 / 2$ and 2/3) are shown in figure 6B. The white arrows in $\mathrm{A}$ indicate wave interactions due to annihilation and wave break up. The rectangles show the positions at which the time traces, shown in figure 8 , have been taken.

Figure 8: Temporal dynamics of the local oscillations as taken from the time-space-plots in figure 7 in (A) agarose, (B) silica (TMOS) and (C) alginate/TMOS gels. The variable locations at which these time traces have been taken are marked by solid black lines (center), solid grey lines (left border) and dashed lines (right border). 


\section{Research highlights}

- Yeast cells immobilized in gels are still active and perform oscillatory glycolysis

- Gel-immobilized yeast cells induce travelling waves of metabolites

- Travelling waves provide for spatial self-organisation and synchronisation of gel-immobilized yeast cells

- Immobilization prolongs the periods of glycolytic oscillations 


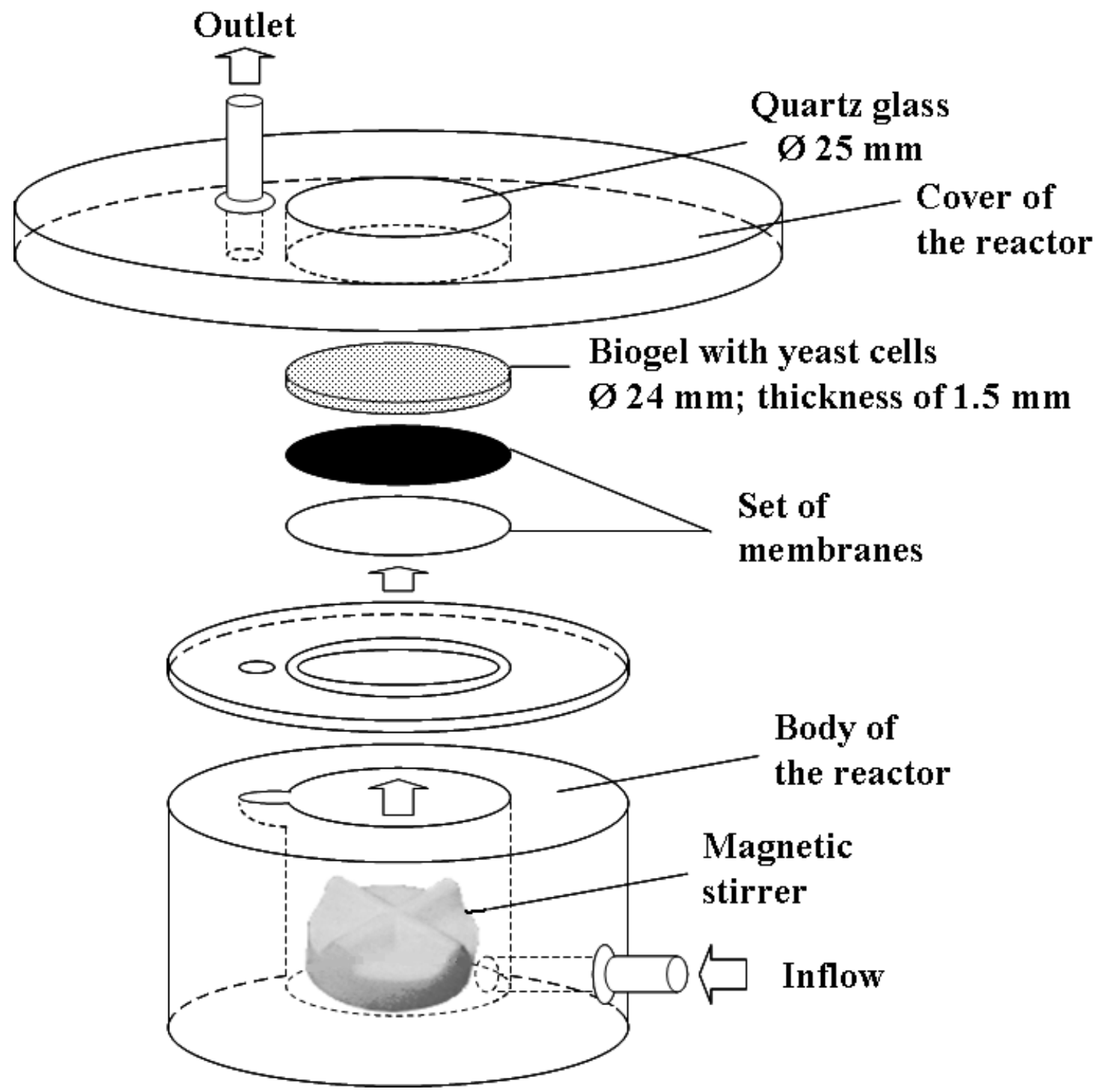

Figure 1 


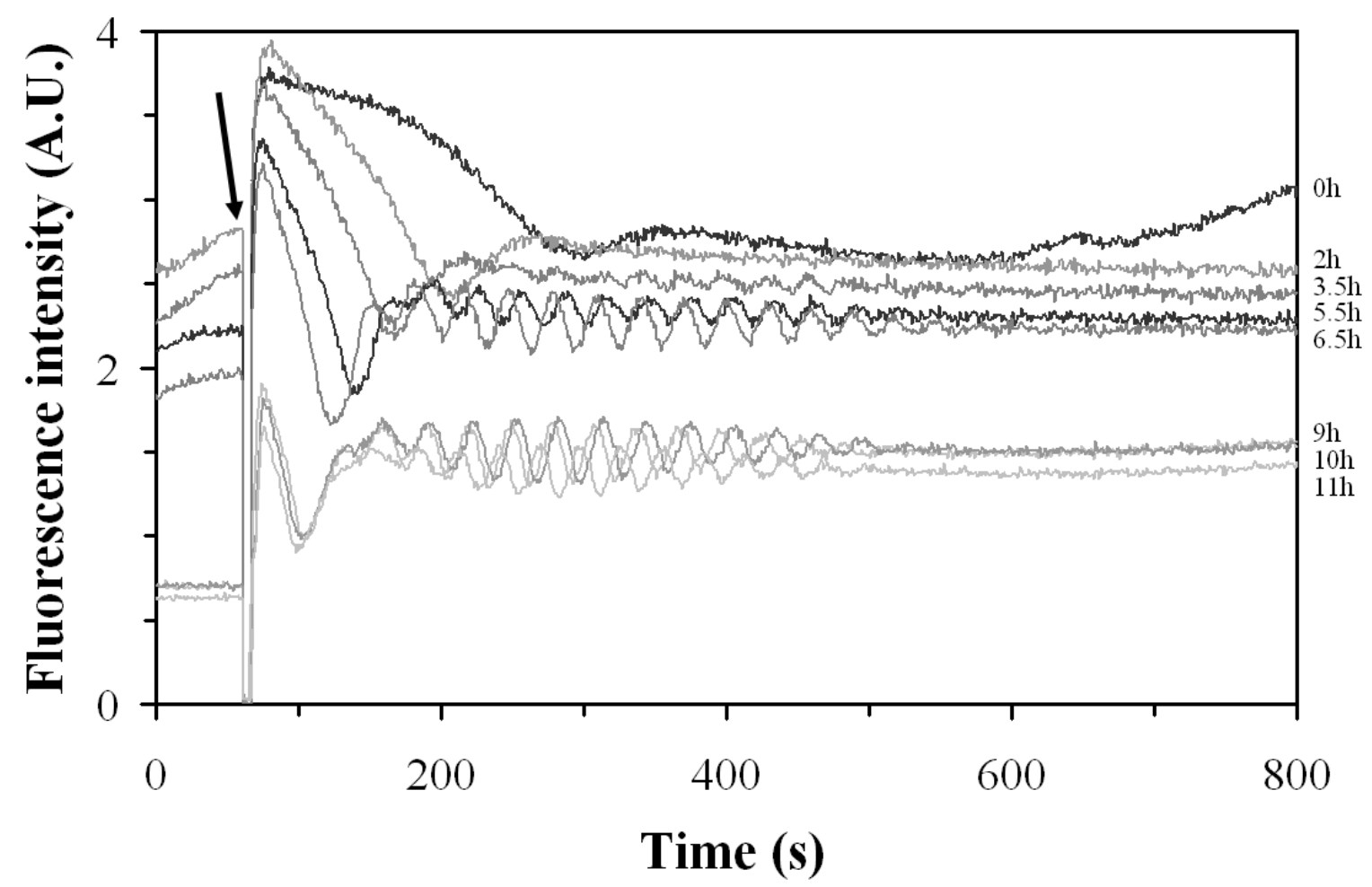

Figure 2 


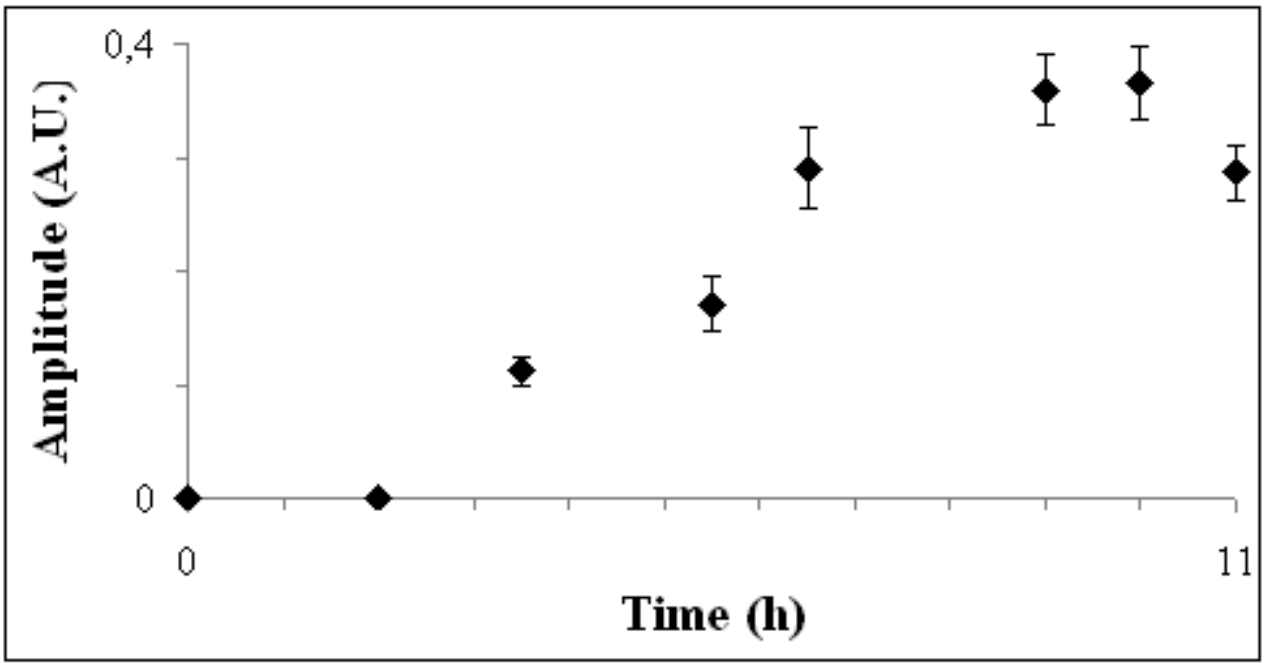

Figure 3 


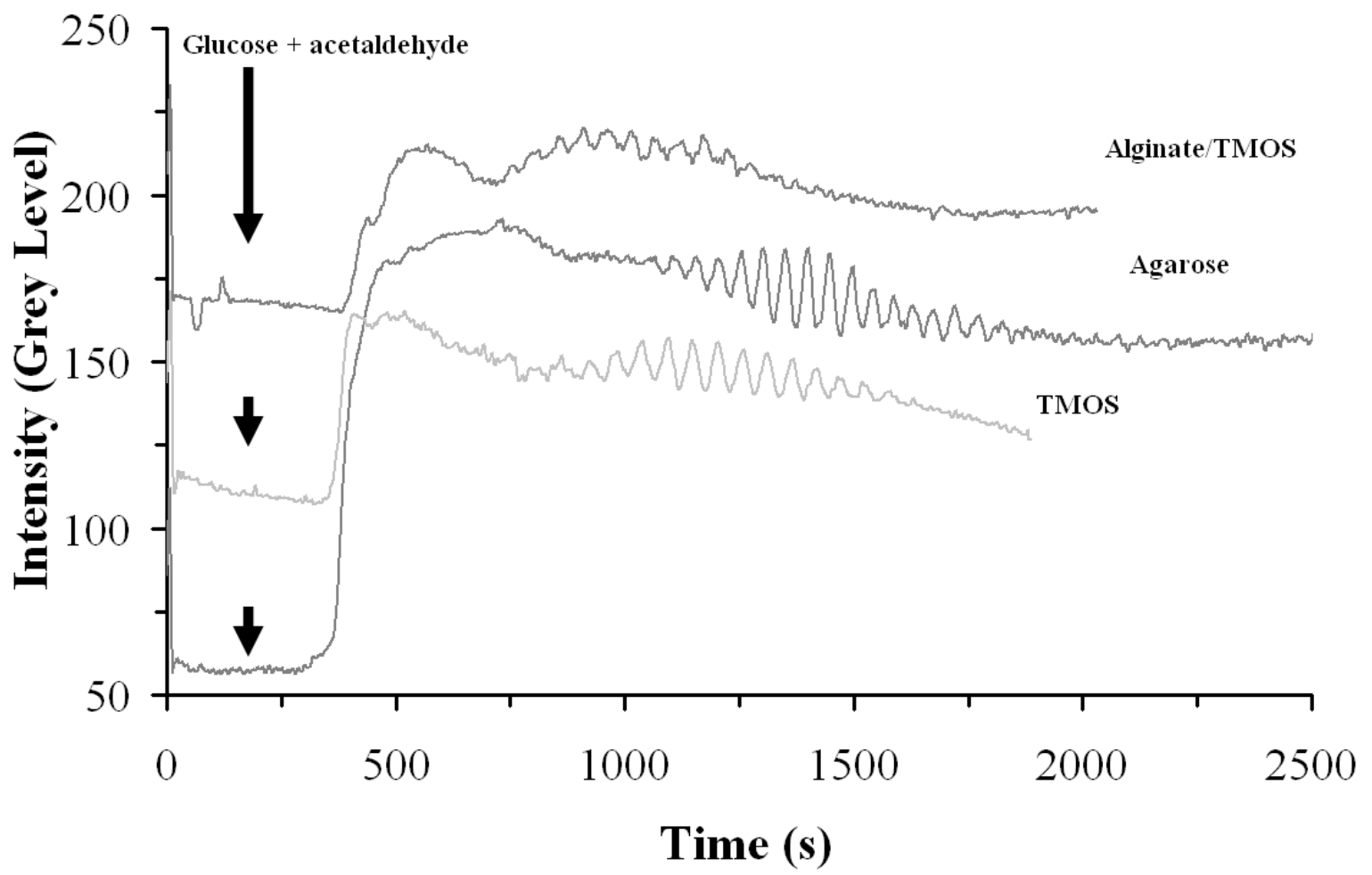

Figure 4 


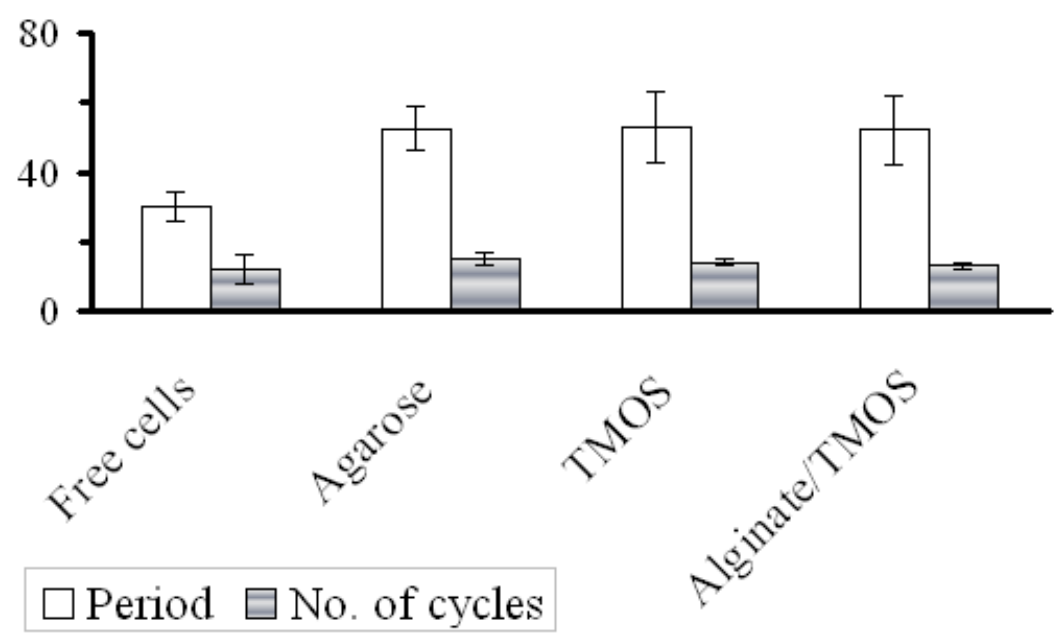

Figure 5 

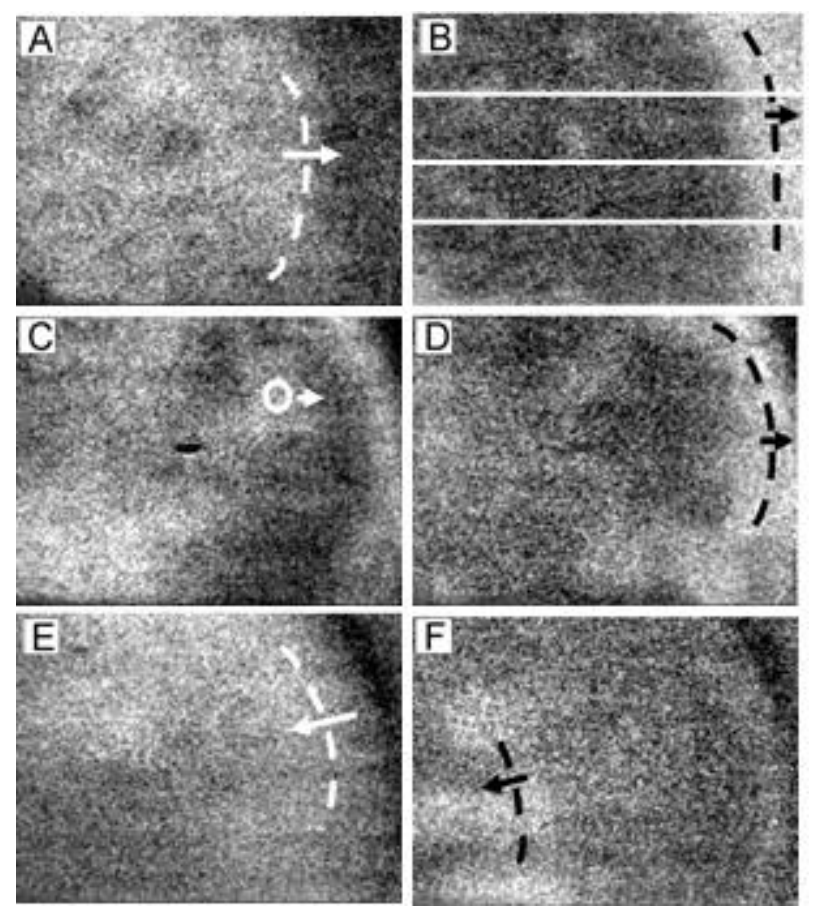

Figure 6 
A

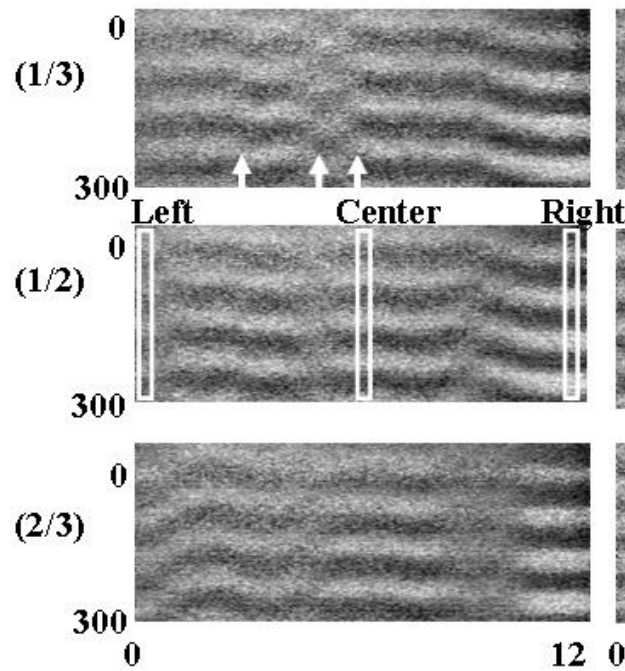

B
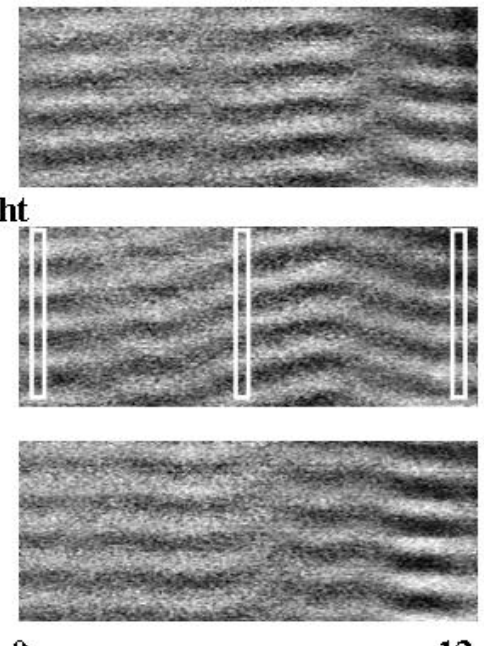

120
C
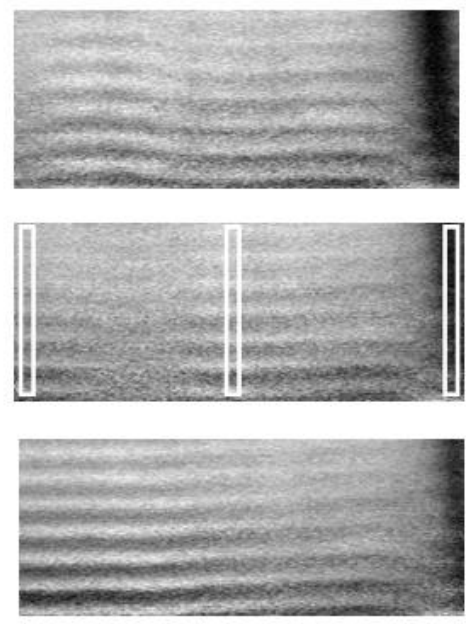

12

Figure 7 

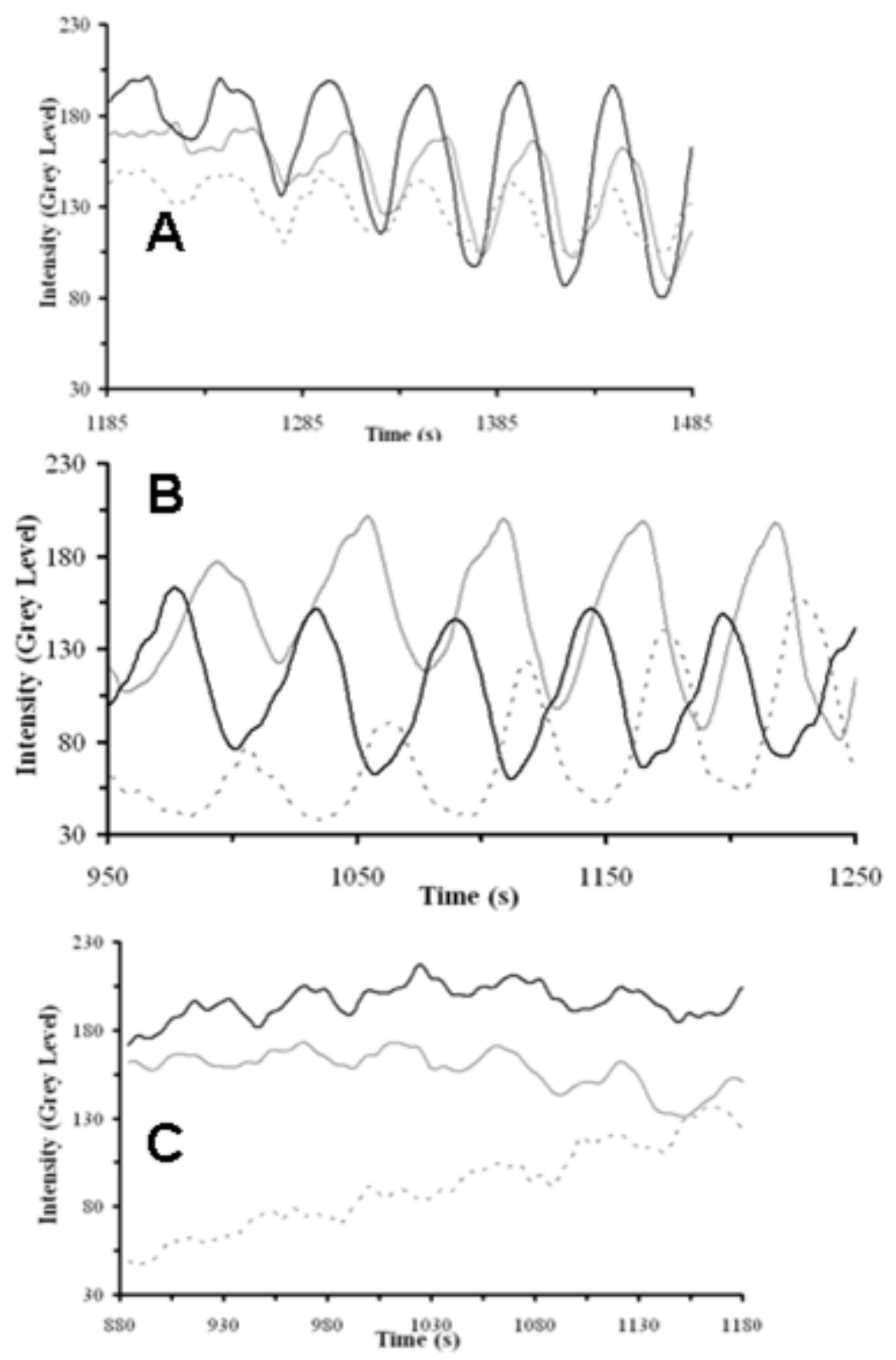

Figure 8 


\section{Graphical Abstract}

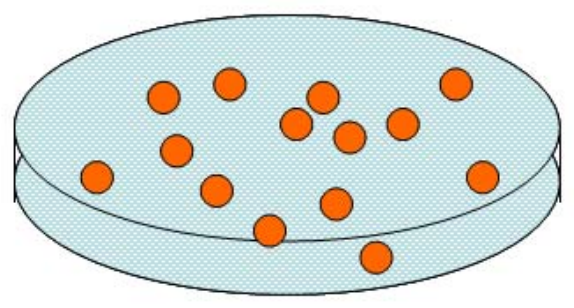

yeast cells immobilized in gels

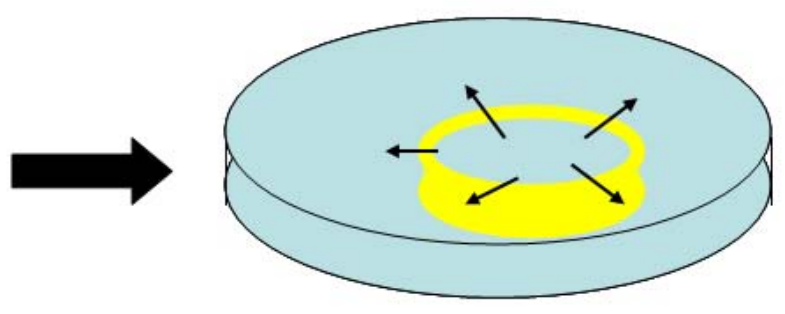

travelling waves of $\mathrm{NAD}(\mathrm{P}) \mathrm{H}$ fluorescence 